\begin{tabular}{ll}
\hline \hline MINING AND METALLURGY INSTITUTE BOR & ISSN: 2334-8836 (Štampano izdanje) \\
UDK: 622 & ISSN: 2406-1395 (Online) \\
\hline \hline
\end{tabular}

UDK: $622.271 / .5(045)=111$

doi:10.5937/mmeb1904043J

Ivana Jovanović, Daniel Kržanović, Vesna Conić, Dejan Bugarin*

\title{
REMOVAL OF A SLUDGE LAYER FROM A PART OF THE OPEN PIT SOUTH MINING DISTRICT MAJDANPEK ${ }^{* *}$
}

\begin{abstract}
This paper describes one of the phases of the technological solution for removal the accumulated material from a part of the Open Pit South Mining District - Copper Mine Majdanpek. It is necessary to clean the material for the purpose of undisturbed further work at the Open Pit. Three layers can be separated in the accumulated material. Each layer requires the use of a different removal technique, where this paper describes the technology of cleaning the middle sludge layer. Hydrocyclone application was proposed to remove the sludge layer, whereby the sludge contains 20-40\% of solids. Classification of the sludge will be performed to obtain the underflow containing about $70 \%$ of solids and overflow containing $7-20 \%$ of the solid phase. The overflow would be gravitationally transported to the water reservoir within the Open Pit, while the underflow would be transported by trucks to a separated waste landfill.
\end{abstract}

Keywords: South Mining District Majdanpek, sludge removal, hydrocyclone, pump

\section{INTRODUCTION}

The Open Pit South Mining District Majdanpek operates within the company Copper Mine Majdanpek, which is a part of the company Zijin Bor Copper doo Company (former Mining and Smelter Basin Bor Group) [1]. Mining activities at the South Mining District Majdanpek currently take place in the eastern side of the Open Pit. The ore excavation takes place at the bench B 215. Based on the current exploitation conditions and situation on the site, the mining operations can be developed to the bench B 140. However, in order to maintain the continuity of ore excavation and to follow the short-term schedule defined in the Annual Operational Plan, it is necessary to enable the development of mining works on the benches B 215 to B 110 within the designed boundaries. This requires the drainage and removal of materials from the water accumulation pool from the level $+150 \mathrm{~m}$ to the bottom of the pit, which is at the level of $+120 \mathrm{~m}$. This is necessary in order to create the conditions for the ore excavation to be carried out smoothly [2].

Material in the accumulation pool comes from excavation works and atmospheric precipitations. According to the assessment, the three layers can be separated:

1. Clean water layer

2. Sludge layer

3. Sediment layer.

\footnotetext{
* Mining and Metallurgy Institute Bor, Zeleni bulevar 35, 19210 Bor, Serbia

** The authors would like to thank to the Ministry of Education, Science and Technological Development of the Republic of Serbia for the financial support in implementation the Project No. TR33007 "Implementation of the Modern Technical, Technological and Ecological Design Solutions in the Existing Production Systems of the Copper Mine Bor and Copper Mine Majdanpek", from which the results presented in this paper were ensued.
} 
It is estimated that the clean water layer is about $8 \mathrm{~m}$ deep with the solid phase concentration below $20 \%$ and the total water volume is $350,000 \mathrm{~m}^{3}$. The sludge layer is about $4 \mathrm{~m}$ deep with the solid phase concentration $20-40 \%$, and the total volume is $156,000 \mathrm{~m}^{3}$. The sediment layer is about $18 \mathrm{~m}$ deep with the solid phase concentration greater than $40 \%$, and the total volume is $460,000 \mathrm{~m}^{3}$. Figure 1 schematically shows the accumulation pool with clearly separated layers.

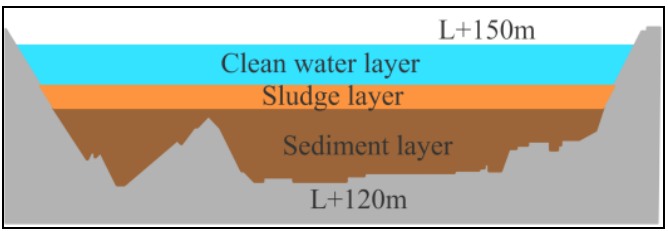

Figure 1 Profile of the accumulated layers

Drainage of the clean water layer will be a cascade type. Submersible pumps will be installed in the accumulation to pump water to the water collector at the level L+180 m, from where will be pumped by the stable pumps to the precipitator for physical treatment the solid particles at the level L+350 $m$ next to the crushing plant. This purified water goes into the existing precipitator with zeolites from which it is discharged into the Mali Pek River.

Cleaning of the sediment layer involves the excavation of material, its loading into trucks and transportation to the waste landfill. This technology is well described in [3].
Removal technology of the sludge layer will be outlined below.

\section{MATERIAL PROPERTIES}

In the Laboratory for Mineral Processing of the Mining and Metallurgy Institute Bor, the $\mathrm{pH}$ value of water, as well as density and particle size distribution were determined on samples from the sludge layer. Particle size distribution is shown in Table 1 . The density of the solid material is $2.764 \mathrm{~kg} / \mathrm{m}^{3}$, while the water $\mathrm{pH}$ is 6.69 . The bulk density of material in the dry state is $1.8 \mathrm{t} / \mathrm{m}^{3}$.

Table 1 Particle size distribution of sample from the sludge layer

\begin{tabular}{|c|c|c|c|}
\hline $\mathbf{d}(\mathbf{m m})$ & $\mathbf{m} \%$ & $\mathbf{R} \%$ & $\mathbf{D} \%$ \\
\hline $\mathbf{- 1 6 . 0 + 1 0 . 0}$ & 10.80 & 10.80 & 100.00 \\
\hline $\mathbf{- 1 0 . 0 + 8 . 0}$ & 2.80 & 13.60 & 89.20 \\
\hline $\mathbf{- 8 . 0 + 3 . 3 5}$ & 0.60 & 14.20 & 86.40 \\
\hline $\mathbf{- 3 . 3 5 + 1 . 7 0}$ & 0.20 & 14.40 & 85.80 \\
\hline $\mathbf{- 1 . 7 0 + 0 . 6 0 0}$ & 0.60 & 15.00 & 85.60 \\
\hline $\mathbf{- 0 . 6 0 0 + 0 . 3 0 0}$ & 0.40 & 15.40 & 85.00 \\
\hline $\mathbf{- 0 . 3 0 0 + 0 . 1 8 0}$ & 1.00 & 16.40 & 84.60 \\
\hline $\mathbf{- 0 . 1 8 0 + 0 . 1 5 0}$ & 1.00 & 17.40 & 83.60 \\
\hline $\mathbf{- 0 . 1 5 0 + 0 . 1 0 6}$ & 2.80 & 20.20 & 82.60 \\
\hline $\mathbf{- 0 . 1 0 6 + 0 . 0 7 5}$ & 4.00 & 24.20 & 79.80 \\
\hline $\mathbf{- 0 . 0 7 5 + 0 . 0 5 3}$ & 3.40 & 27.60 & 75.80 \\
\hline $\mathbf{- 0 . 0 5 3 + 0 . 0 3 8}$ & 6.00 & 33.60 & 72.40 \\
\hline $\mathbf{- 0 . 0 3 8 + 0 . 0 2 0}$ & 9.20 & 42.80 & 66.40 \\
\hline $\mathbf{- 0 . 0 2 0 + 0 . 0 0 0}$ & 57.20 & 100.00 & 57.20 \\
\hline
\end{tabular}

In order to gain a clearer insight into the distribution of fine particles in the sample of sludge from the accumulation pool, an addi- tional testing of class $-0.180+0 \mathrm{~mm}$ is performed on a Malvern Mastersizer 2000 device. The results are shown in Figure 2. 


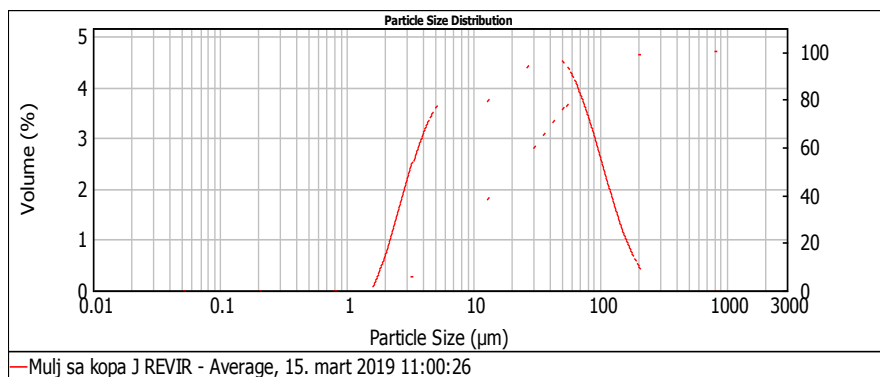

Figure 2 Particle size distribution of sample from the sludge layer (class $-0.180+0 \mathrm{~mm}$ )

\section{PROCEDURE FOR A SLUDGE LAYER REMOVAL}

The technical solution of cleaning the deposited material in a sludge layer from a part of the Open Pit South Mining District Majdanpek is presented in accordance with the basic data and requirements provided by the Zijin Bor Copper doo Company.

The planned procedure would include the following: material would be pumped out with a centrifugal slurry pump installed at the pontoon pump station, which can be moved as needed (in accordance with the operating requirements). The pumped material would be transported through the pipeline to the hydrocyclone battery for classification, i.e. for separation into the underflow and overflow. Hydrocyclones are located near the water collector, on its north side, at the elevation of $\mathrm{L}+135 \mathrm{~m}$.

The hydrocyclone underflow, containning $70 \%$ of the solids, will be deposited at the site provided therein within the Open Pit, northern from the existing water collector. The settled underflow would be further loaded onto trucks by the excavator, and transported to a landfill outside the open pit. The overflow, which, depending on the amount of solids content in the feed pulp, contains $7.5-20 \%$ of solids, would be transported to the existing water collector at the level $\mathrm{L}+125 \mathrm{~m}$. From there, water will be further pumped into the Mali Pek River. The technological scheme of sludge layer cleaning is shown in Figure 3.

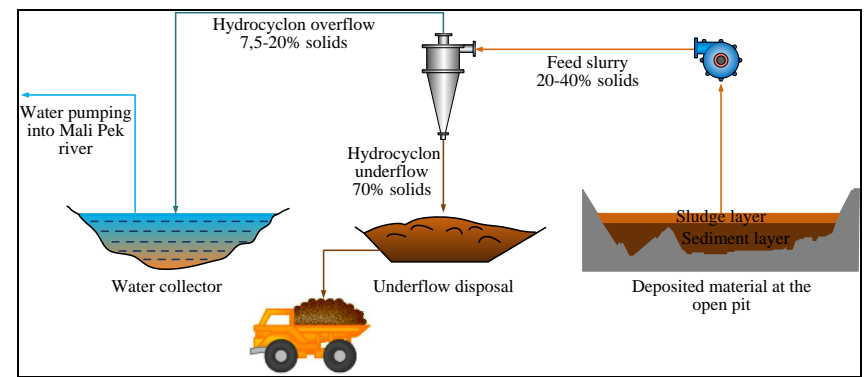

Figure 3 Technological scheme of pumping and cycloning of the sludge layer

The expected processing rate of the system is $1,019.46 \mathrm{~m}^{3} / \mathrm{h}$ with the solid phase content in the feed slurry $20-40 \%$. Thereby, the expected underflow rate is $221 \mathrm{~m}^{3} / \mathrm{h}$ (percentage of solids in the underflow is $70 \%$ ). On the other hand, the volume rate of overflow, as well as its pulp density, will vary depending on the feed parameters. As the basic data for the mass balance calculation, the mean value of solid content in the feed slurry is taken and it amounts $30 \%$. Mass balance is shown in Table 2 and 
corresponds to the given input parameters. Each change in the composition of the feed

slurry consequently influences a change in mass balance.

Table 2 Mass balance in the process of sludge layer cycloning

\begin{tabular}{|l|r|r|r|}
\hline \multicolumn{1}{|c|}{ Technological line } & \multicolumn{1}{c|}{ Feed } & \multicolumn{1}{c|}{$\begin{array}{c}\text { Hydrocyclone } \\
\text { underflow }\end{array}$} & $\begin{array}{c}\text { Hydrocyclone } \\
\text { overflow }\end{array}$ \\
\hline Dry ore quantity, $\mathrm{Q}(\mathrm{t} / \mathrm{h})$ & 378.26 & 279.62 & 98.64 \\
\hline Water quantity, $\mathrm{Q}_{\mathrm{W}}(\mathrm{t} / \mathrm{h})$ & 882.61 & 119.84 & 762.77 \\
\hline Slurry quantity, $\mathrm{Q}_{\mathrm{S}}(\mathrm{t} / \mathrm{h})$ & $1,260.87$ & 399.46 & 861.41 \\
\hline Ore density, $\rho\left(\mathrm{kg} / \mathrm{m}^{3}\right)$ & $2,764.0$ & $2,764.0$ & $2,764.0$ \\
\hline Percentage of solids, $\mathrm{S}(\%)$ & 30 & 70 & 11.45 \\
\hline Slurry density, $\rho_{\mathrm{S}}\left(\mathrm{kg} / \mathrm{m}^{3}\right)$ & $1,236.80$ & $1,807.48$ & 35.078 \\
\hline Ore volume, $\mathrm{V}\left(\mathrm{m}^{3} / \mathrm{h}\right)$ & $1,36.85$ & 101.16 & 762.77 \\
\hline Water volume, $\mathrm{V}_{\mathrm{W}}\left(\mathrm{m}^{3} / \mathrm{h}\right)$ & 882.61 & 119.84 & 798.46 \\
\hline Slurry volume, $\mathrm{V}_{\mathrm{S}}\left(\mathrm{m}^{3} / \mathrm{h}\right)$ & $1,019.46$ & 221.00 & \\
\hline
\end{tabular}

In order to reconcile the capacity of cycloning plant with the capacity of truck transport, the plant is scheduled for 8 days operation, in three shifts, 20 working hours per day.

Considering the slurry characteristics, its transport capacity of $1,019.46 \mathrm{~m}^{3} / \mathrm{h}$, the pumping height difference of $28 \mathrm{~m}$, and the transport length of $600 \mathrm{~m}$, installation of two centrifugal slurry pumps $\left(\mathrm{Q}=1,271 \mathrm{~m}^{3} / \mathrm{h}\right.$; $\mathrm{H}=64.6 \mathrm{~m}, \mathrm{Ne}=355 \mathrm{~kW}$ ) are predicted. One pump will be in operation and one is for reserve.

In the slurry cycloning procedure, it is planned the installation of 12 hydrocyclones with a diameter of $500 \mathrm{~mm}$. Depending on the working conditions, i.e. the density of the feed slurry, a different number of hydrocyclones will be used (6-9), while the other hydrocyclones will serve as a reserve.

For the slurry transportation, it is planned the installation of the polyethylene pipeline with the pipe diameter of $250 \mathrm{~mm}$.

\section{CONCLUSION}

The accumulation pool is located in a part of the Open Pit South Mining District Majdanpek, consisting of material from the excavation works and atmospheric precipitation. In order to create the conditions for the undisturbed ore exploitation, it is necessary to clean this material from the Open Pit. The accumulated material can be separated into three layers (water, sludge and sediment), where each layer requires the use of a different removal technique. The hydrocyclone technology will be applied for clean- ing the middle sludge layer. Slurry from this layer will be classified into the underflow containing about $70 \%$ of solids and overflow containing $7-20 \%$ of solids. The underflow would be transported by trucks to a separated waste landfill, while the overflow would be gravitationally transport-ted to the water reservoir within the Open Pit. The expected feed slurry capacity is $1,019.46 \mathrm{~m}^{3} / \mathrm{h}$, where the underflow capacity amounts $221 \mathrm{~m}^{3} / \mathrm{h}$. The proposed technology involves the installation of two centrifugal slurry pumps, a 600 $\mathrm{m}$ long pipeline and a battery of 12 hydrocyclones.

\section{REFERENCES}

[1] D. Kržanović, M. Ljubojev, I. Jovanović, N. Vušović, An Analysis the Effects of Changes in Price of Metal and Operating Costs to the Profit in Exploitation the Copper Ore Deposits, A Case Study: Copper Mine Majdanpek, Serbia, MME Bor 3-4,2017, 51-58

[2] D. Kržanović et all., Technical Solution for the Open Pit South Mining District Drainage for Clear Water, Cleaning of Slurry, Cleaning of Sediment, Water Control and Waste Sampling and Testing, Mining and Metallurgy Institute Bor, 2019.

[3] D. Kržanović, V. Kostić, R. Rajković, I. Jovanović, Establishing the Spatial Conditions at the South Mining District Majdanpek to Achieve the Continuity in Ore Mining: a Proposed Technology for Sediment Layer Removal, MME Bor 1-2, 2019, pp. 1-8. 